\title{
Pengaruh Variasi Arus Pengelasan dan Debit Aliran Gas Pelindung Terhadap Kekuatan Tarik Stainless Steel 304 pada Proses Las GTAW
}

\author{
Ahmad Saefudin ${ }^{1}$, Abdul Qolik ${ }^{2}$, Solichin $^{3}$ \\ 1,2,3 Program Studi S1 Pendidikan Teknik Mesin Jurusan Teknik Mesin \\ ${ }^{1,2,3}$ Fakultas Teknik Universitas Negeri Malang \\ 1,2,3 Jalan Semarang No. 5, Malang 65145 \\ E-mail: ahmadsaefudinum@gmail.com1
}

\begin{abstract}
Abstrak: Tujuan dari penelitian ini untuk mengetahui kekuatan tarik stainless steel 304 dari pengelasan GTAW dengan variasi kuat arus dan debit aliran gas. Metode penelitian yang digunakan adalah penelitian eksperimental dengan variasi kuat arus 80A, 90A dan 100A dan debit aliran gas pelindung sebesar $8 \mathrm{~L} /$ menit dan $10 \mathrm{~L} /$ menit. Sampel untuk pengujian menggunakan standar uji ASTM E8/E8M-09. Hasil analisis statistik kuat arus menunjukkan bahwa nilai signifikansi sebesar 0.032 lebih kecil dari 0,05 , atau $\mathrm{H} 0$ ditolak artinya penggunaan variasi kuat arus berpengaruh terhadap kekuatan tarik. Sedangkan analisis statistik untuk dabit aliran gas palindung menunjukkan bahwa nilai signifikansi sebesar 0.144 lebih besar dari 0,05 , atau H0 tidak ditolak artinya penggunaan variasi debit aliran gas pelindung tidak berpengaruh terhadap kekuatan tarik. Nilai kekuatan tarik tertinggi terdapat pada penggunaan arus 90A dengan debit aliran gas 8 $\mathrm{L} /$ menit sebesar 610,54 Mpa. Nilai kekuatan tarik terendah terdapat pada penggunaan arus 80A dengan debit aliran gas 10 $\mathrm{L} /$ menit sebesar 560,89 Mpa.
\end{abstract}

Kata Kunci: Stainless Steel, GTAW, Kua Tarik, Tungsten Inert Gas

\begin{abstract}
The purpose of this study was to determine the tensile strength of stainless steel 304 from GTAW welding with variations in current strength and gas flowrate. The research method used was an experimental study with strong variations in current $80 \mathrm{~A}, 90 \mathrm{~A}$ and $100 \mathrm{~A}$ and protective gas flow rates of $8 \mathrm{~L} / \mathrm{min}$ and $10 \mathrm{~L} / \mathrm{min}$. Samples for testing use the ASTM E8 / E8M-09 test standard. The result of statistical analysis of current strength shows that the significance value of 0.032 is less than 0.05 , or $\mathrm{H} 0$ is rejected, meaning that the use of strong current variations affects the tensile strength. While the statistical analysis for the dabit of the protected gas flow shows that the significance value of 0.144 is greater than 0.05 , or $\mathrm{H} 0$ is not rejected, meaning that the use of protective gas flowrate variations does not affect the tensile strength. The highest value of tensile strength is in the use of 90A current with $8 \mathrm{~L} /$ min gas flowrate of 610.54 $\mathrm{MPa}$. The lowest tensile strength value is found in the use of $80 \mathrm{~A}$ current with $10 \mathrm{~L} /$ min gas flowrate of $560.89 \mathrm{MPa}$.
\end{abstract}

Keywords: Stainless Steel, GTAW, Kua Pull, Tungsten Inert Gas

Hampir seluruh pengerjaan logam di era sekarang tidak terlepas dari yang namanya pengelasan. Berbagai standartstandart las yang telah ditemukan para peneliti terdahulu sangat memberikan kemudahan bagi peneliti muda saat ini. Seiring bertambahnya waktu makin banyak pula jenis material-material yang akan diciptakan untuk memenuhi kebutuhan masyarakat dalam mengembangkan usahanya dibidang manufaktur. Sehingga dalam hal ini penelitian terkait pengelasan terus menerus dilakukan agar mendapatkan pengerjaan-pengerjaan sambungan lasan yang baik.

Stainless steel merupakan baja tahan karat yang banyak digunakan masyarakat. Stainless steel mempunyai keunggulan yaitu tahan korosi, tahan terhadap oksidasi pada temperatur tinggi dan mempunyai hardenability yang tinggi (Marihot, 1984: 73). Dalam lingkup rumah tangga Stainless steel banyak digunakan sebagai tempat pengolahan dan penyimpanan makanan misalnya seperti alat penggorengan. Dalam lingkup kesehatan, selain sifatnya yang bersih dan menarik, Stainless steel dipilih untuk kebutuhan alat-alat medis seperti pisau bedah, agar kesterilannya selalu terjaga.

Dalam hal industri terutama industri kereta api, Stainless steel merupakan bahan utama yang digunakan sebagai bahan pembuatan gerbong kereta api stainless dimana penerapan bahan ini meliputi bagian frame, roof, sidewall, dan endwall gerbong kereta api. Akan tetapi untuk underframe nya menggunakan mildsteel Dan masih banyak lagi kegunaan Stainless steel dalam industry maupun dalam kehidupan sehai-hari.

Dari berbagia jenis las yang telah diciptakan yang cocok untuk memenuhi kebutuhan konstruksi dari bahan stainlees steel adalah pengelasan GTAW. Pengelasan GTAW adalah jenis las yang menggunakan bahan tungsten sebagai elektroda tidak terkonsumsi (Widharto, 2003: 195). Elektroda pada mesin las GTAW ini hanya menghasilkan busur nyala listrik. Busurnyala listrik akan melelehkan bahan penambah untuk mengisi sambungan logam. Pengelasan GTAW ini menghasilkan kualitas lassan yang sangat baik, tidak menghasilkan terak sama sekali.

Seperti yang dikemukakan oleh Wiryosumarto (2008:1) bahwa perancangan konstruksi bangunan dan mesin dengan sambungan las, harus direncanakan tentang cara pengelasan, cara pemeriksaan, bahan las, dan jenis las yang akan dipergunakan 
berdasarkan fungsi dari bagian-bagian bangunan atau mesin yang dirancang. Proses pengelasan telah banyak terjadi pada banyak proses pengerjaan akan tetapi perlu juga diketahui bersama apa dampak yang dihasilkan berbagai macam proses pengelasan, posisi pengelasan, gerakan proses kawat las, kuat arus yang digunakan pada proses pengelasan yang dilakukan. Karena dari berbagai macam metode akan terjadi ketidak samaan hasil pengelasan.

Arus listrik adalah banyaknya muatan listrik yang bergerak melalui suatu penampang konduktor persatuan waktu karena medan listrik (Sunarto, 2015: 71). Penentuan jenis arus juga mempengaruhi kedalaman penetrasi yang akan dibentuk. Dalam pengelasan tentunya kita membutuhkan panas yang lebih pada benda kerja yang dilas. Apabila kita menggunakan AC maka distribusi panasnya terjadi $1 / 2$ untuk benda kerja dan 1/2 untuk elektroda. Pada arus Direct Current Elektrode Positif (DCEP) 2/3 panas terjadi pada elektroda dan dan 1/3 sisanya terjadi pada benda kerja. Sedangkan pada arus Direct Current Elektrode Positif (DCEN) terjadi sebaliknya yaitu 1/3 panas untuk electrode dan $2 / 3$ panas untuk benda kerja. Sehingga dari distribusi panas yang berbeda ini akan mempengaruhi kedalaman penetrasi. Oleh karena itu polaritas yang paling bagus digunakan pada pengelasan stainless steel ini adalah polaritas DCEN (ASM Vol 6 1993: 596)

Pada pengelasan GTAW gas pelindung yang digunakan adalah gas argon, karena mampu mengurangi difusi hidrogen. Salah satu cara untuk menghindari patah dan retak akibat difusi hidrogen yaitu dengan menggunakan gas pelindung untuk mencegah agar hidrogen yang terdapat pada atmosfir tidak terserap pada logam cair pada saat proses pengelasan (Ismawan, 2010). Hal ini sesuai dengan apa yang di kemukakan oleh Widharto,(2006:162) yaitu fungsi utama debit aliran gas pelindung adalah mengusir udara di lingkungan busur dan kolam las agar tidak bersinggungan dengan cairan metal untuk mencegah proses terjadinya oksidasi metal tersebut dengan udara. Dari beberapa uraian latar belakang dan fenomena hasil penelitian yang telah dilakukan sebelumnya, maka penulis berkeinginan untuk mengadakan penelitian dengan judul "Pengaruh Variasi Arus Pengelasan Dan Debit Aliran Gas Pelindung Terhadap Kekuatan Tarik Stainless steel 304 Pada Proses Las GTAW"

Pengujian tarik merupakan pengujian yang digunakan untuk mengetahui sifat mekanik logam yang penting, karena merupakan dasar untuk perencanaan pemesinan. Dengan dilakukannya pengujian tarik dapat diketahui sfat-sifat seperti:

\section{Kekuatan tarik maksimun ( $\sigma)$}

Merupakan kemampuan maksimal dari material dalam menerima tegangan yang diberikan sebelum mengalami pepatahan (fracture). Pada material yang memiliki sifat elastis umumnya terjadi penurunan tegangan terlebih dahulu sebelum terjadi patah. Kekuatan tarik dapat dirumuskan (Dieter, 1988:279) :

$\sigma_{\mathrm{u}}=\frac{F u}{A o}$

Dimana, $\sigma_{\mathrm{u}}=$ tegangan tarik maksimum

$F_{u}=$ Gaya terbesar $(\mathrm{N})$

Ao $=$ luas penampang semula $\left(\mathrm{mm}^{2}\right)$

\section{Regangan ( $(\varepsilon)$}

Merupakan pertambahan panjang benda akibat dari pembebanan pengujian tarik. Dirumuska:

$\varepsilon=\frac{L-L O}{L o} \times 100 \%$

Dimana, = regangan $(\%)$

$\mathrm{L}=$ panjang akhir benda $(\mathrm{mm})$

Lo $=$ panjang awal benda $(\mathrm{mm})$

Tegangan dapat dituliskan dengan satuan $\mathrm{kg} / \mathrm{mm}^{2}, \mathrm{~kg} / \mathrm{cm}^{2}$, psi (Pounds per Square Inch) atau Mpa, sedangkan regangan merupakan pertambahan panjang benda yang dapat dituliskan dengan satuan $\%$ atau $\mathrm{mm} / \mathrm{mm}$.

\section{METODE PENELITIAN}

Bahan yang digunakan untuk penelitian ini adalah stainless steel 304, Filler metal menggunakan jenis AWS A5.9/ER 308. Dan gas pelindung yang digunakan adalah gas Argon (Ar) 95\%

Alat yang digunakan penelitian meliputi : Mesin las GTAW (TIG), mesin uji Tarik Universal Testing Machine (UTM), tang Ampere (Clam Meter), gergaji mesin, gerinda tangan, mesin Frais, kamera, jangka sorong, palu, kikir

Table 1. Rancangan Penelitian Analisis Kekuatan Tarik Stainless steel 304 Variasi Kuat Arus dengan Debit Aliran Gas Pelindung

\begin{tabular}{|c|c|c|c|c|}
\hline \multirow{2}{*}{\multicolumn{2}{|c|}{ Debit A liran Gas }} & \multicolumn{3}{|c|}{ Variasi Kuat Arus } \\
\hline & & $80 \mathrm{~A}$ & $90 \mathrm{~A}$ & $100 \mathrm{~A}$ \\
\hline \multirow{5}{*}{ 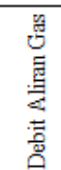 } & \multirow{3}{*}{8 LMenit } & $\mathrm{X}_{11}$ & $\mathrm{X}_{21}$ & $\mathrm{X}_{31}$ \\
\hline & & $\mathrm{X}_{12}^{2-1}$ & $\mathrm{X}_{22}$ & $\mathrm{X}_{32}$ \\
\hline & & $\mathrm{X}_{13}$ & $\mathrm{X}_{23}$ & $\mathrm{X}_{33}$ \\
\hline & \multirow[b]{2}{*}{10 L/Menit } & $Y_{11}$ & $\mathrm{Y}_{21}$ & $Y_{31}$ \\
\hline & & $\mathrm{Y}_{12}$ & $\mathrm{Y}_{22}$ & $\mathrm{Y}_{32}$ \\
\hline
\end{tabular}


Rancangan penelitian yang digunakan pada penelitian ini adalah rancangan penelitian eksperimental seperti pada tabel 1. Variabel bebas yang digunakan adalah variasi kuat arus $80 \mathrm{~A}, 90 \mathrm{~A}$ dan $100 \mathrm{~A}$. dengan debit aliran gas pelindung sebesar 8 L/menit dan $10 \mathrm{~L} /$ menit. sedangkan variabel terikatnya kekuatan tarik dari Stainless steel 304. Dalam penelitian ini jumlah spesimen yang digunakan peneliti sebanyak 18 spesimen uji tarik, dengan tiap variabel penelitian dilakukan sebanyak tiga kali dengan asumsi sudah dapat mewakili hasil dengan mengambil rata-rata.

\section{Persiapan Benda Uji}

Benda uji penelitian dari material stainless steel 304 dengan model sambungan las menggunakan kampuh V-tunggal dengan sudut kampuh $60^{\circ}$, root gap $2 \mathrm{~mm}$, root face $1 \mathrm{~mm}$ pada ketebalan benda $5 \mathrm{~mm}$. pengerjaan pembuatan spesimen yang meliputi pemotongan material, pembuatan kampuh, dan pembentukan spesimen uji tarik dilakukan dengan pengerjaan dingin, hal ini bertujuan agar tidak merubah sifat mekanik dari material stainless steel 304 karena adanya pengaruh panas yang timbul saat proses pengerjaan terjadi. Untuk ukuran dan bentuk spesimen uji tarik menggunakan standar yang ditetapkan ASTM E8/E8M-09, lihat pada gambar 2. Adapun diagram alir penelitian ditunjukan pada gambar 3.

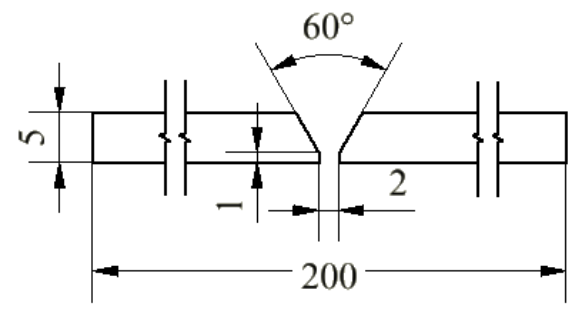

Gambar 1. Ukuran kampuh las

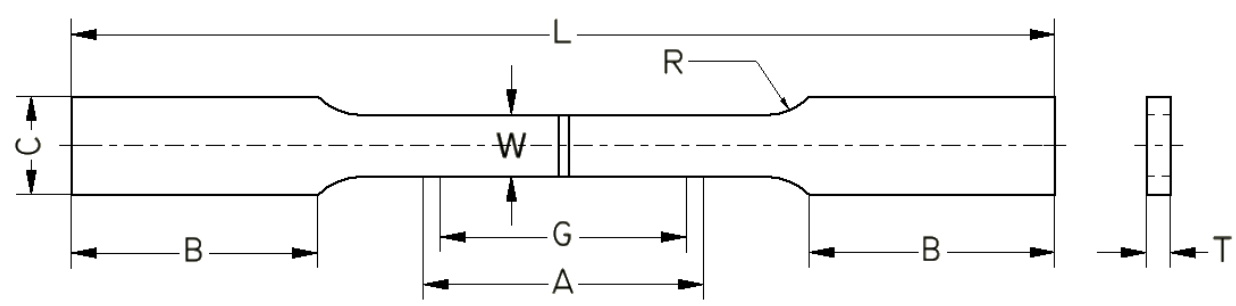

Gambar 2. Bentuk dan Ukuran Spesimen Uji Tarik

Keterangan (dalam mm):

Gage length $(\mathrm{G}) \quad: 50$

Width (W) $\quad: 12,5 \pm 0,2$

Thickness $: 5$

Radius of fillet (R) $\quad: 12,5$

Overall Length (L) : : 200

Length of reduced section (A) : 57

Length of grip section (B) $\quad: 50$

Width of grip section (C) : 20 


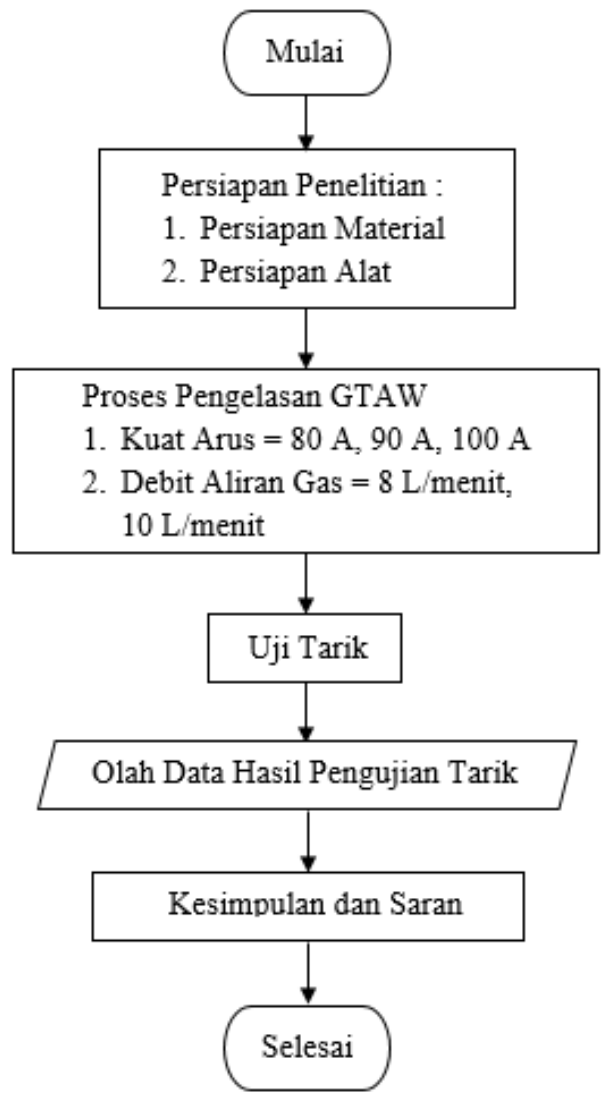

Gambar 3. Diagram Alir Penelitian

\section{HASIL DAN PEMBAHASAN}

Dari hasil pengujian tarik yang dilakukan menggunakan mesin uji tarik universal testing machine, diperoleh data sebagai berikut:

Table 2. Hasil Pengujian Kekuatan Tarik Spesimen Stainless Steel 304 Untuk Berbagai Variasi Arus Dan Debit Aliran Gas Pelindung

\begin{tabular}{ccccc}
\hline \multirow{2}{*}{$\begin{array}{c}\text { Kuat arus } \\
(\mathbf{A})\end{array}$} & $\begin{array}{c}\text { Debit } \\
\text { aliran gas } \\
(\mathbf{L} / \text { menit })\end{array}$ & $\begin{array}{c}\boldsymbol{\sigma} \text { luluh } \\
\left(\boldsymbol{\sigma}_{\boldsymbol{y}}\right) \\
(\mathbf{M p a})\end{array}$ & $\begin{array}{c}\boldsymbol{\sigma} \text { tarik } \\
\left(\boldsymbol{\sigma}_{\boldsymbol{u}}\right)\end{array}$ & $\begin{array}{c}\text { Regangan } \\
(\boldsymbol{(})\end{array}$ \\
\hline \multirow{2}{*}{80} & 8 & 329,16 & 569,67 & $(\boldsymbol{M})$ \\
\hline \multirow{2}{*}{90} & 10 & 193,51 & 560,89 & 8,12 \\
\hline \multirow{2}{*}{100} & 8 & $328,94$. & 610,54 & 9,46 \\
& 10 & 252,38 & 590,60 & 9,12 \\
\hline & 8 & 266,25 & 587,58 & 9,08 \\
\hline
\end{tabular}




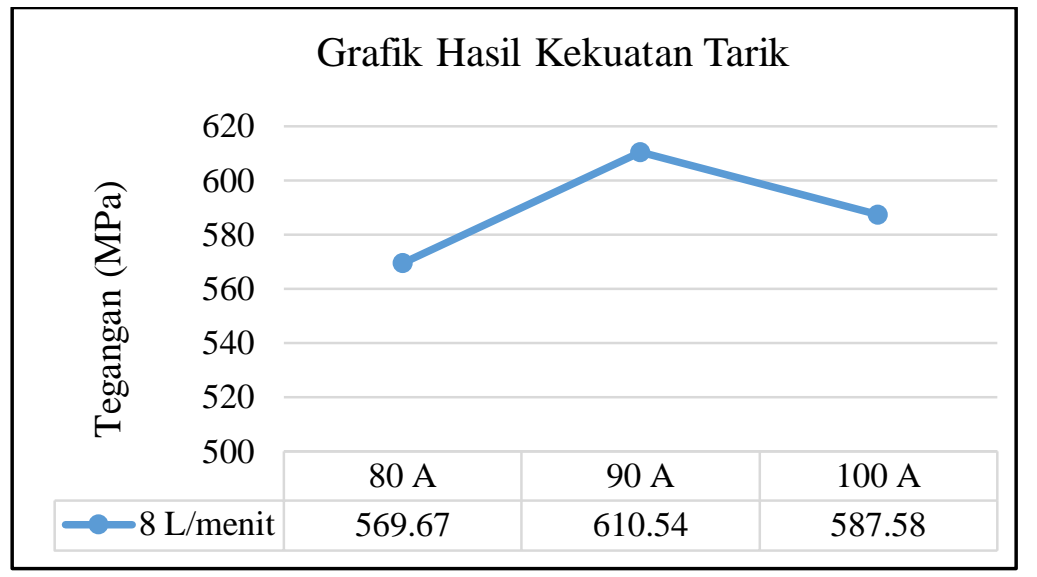

Gambar 4 Grafik Pengujian Tarik Pada Pengelasan Stainless Steel 304 dengan Variasi Arus 80 A, 90 A, 100 A dan Debit Aliran Gas 8 L/menit

Dari gambar diatas terjadi perbedaan kekuatan tarik spesimen pada penggunaan debit aliran gas $8 \mathrm{~L} / \mathrm{menit}$ dengan variasi kuat arus. Pada perlakuan ini kekuatan tarik tertinggi terletak pada arus 90 A yaitu sebesar 610,54 Mpa. Sedangakan kekuatan tarik yang paling rendah terdapat pada kuat arus 80 A yaitu sebesar 569,67 Mpa.

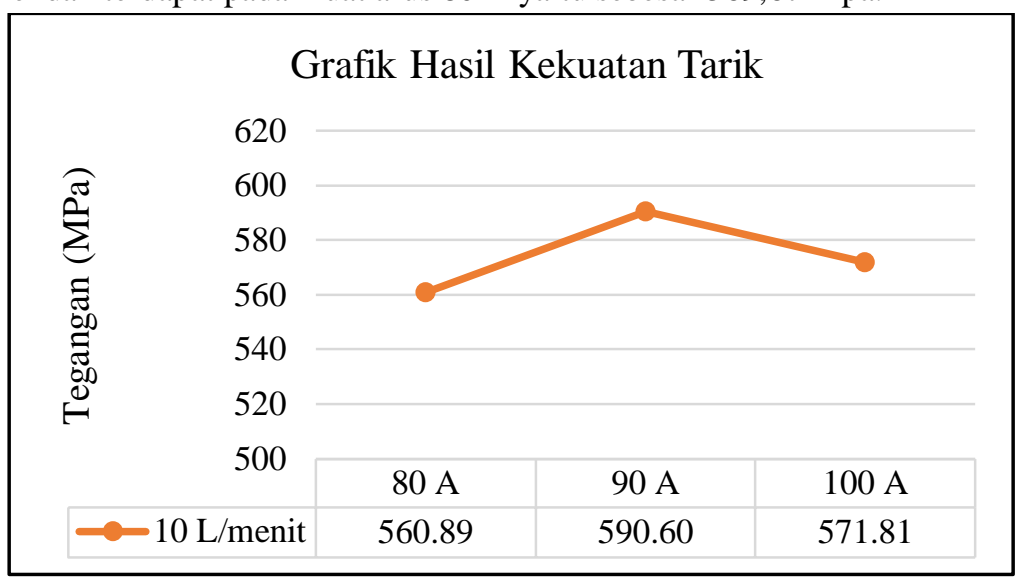

Gambar 5. Grafik Pengujian Tarik Pada Pengelasan Stainless Steel 304 Dengan Variasi Arus 80 A, 90 A, 100 A dan Debit Aliran Gas 10 L/Menit

Dari gambar 5 diatas terlihat bahwa terjadi perbedaan kekuatan tarik spesimen pada penggunaan debit aliran gas 10 L/menit dengan variasi kuat arus. Pada perlakuan ini kekuatan tarik tertinggi terletak pada arus 90 A yaitu sebesar 590,60 Mpa. Sedangakan kekuatan tarik yang paling rendah terdapat pada kuat arus $80 \mathrm{~A}$ yaitu sebesar 560,89 Mpa.

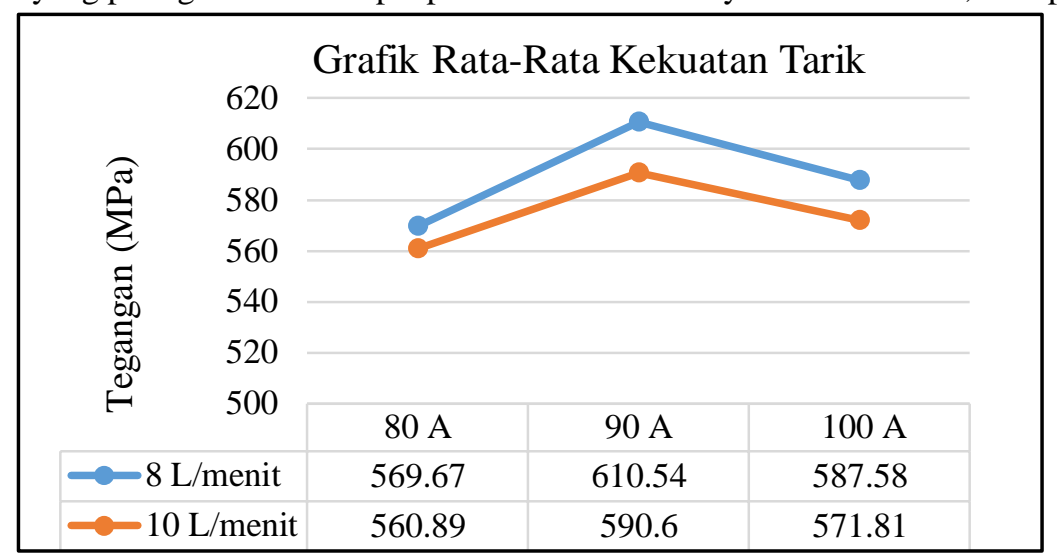

Gambar 6. Grafik Nilai Rata-Rata Pengujian Tarik Yang Telah Mengalami Pengelasan GTAW 
Pada gambar 6 diatas, hasil pengujian menunjukan bahwa terdapat selisih kekuatan tarik stainless steel 304 antara penggunaan debit aliran gas $8 \mathrm{~L} /$ menit dengan $10 \mathrm{~L} /$ menit. Pada penggunaan arus 80A terdapat selisih sebesar 8,78 Mpa lebih besar yang menggunakan debit aliran gas $8 \mathrm{~L} /$ menit. Kemudian pada penggunaan arus 90A terdapat selisih sebesar $19,94 \mathrm{Mpa}$ lebih besar yang menggunakan debit aliran gas $8 \mathrm{~L} /$ menit. Sedangkan pada penggunaan aurs $100 \mathrm{~A}$ terdapat selisih sebesar 15,77 Mpa lebih besar yang menggunakan debit aliran gas $8 \mathrm{~L} /$ menit.

Pada kuat arus $80 \mathrm{~A}$ rata-rata memiliki nilai kekuatan tarik yang rendah hal ini disebabkan karena masukan panas yang kurang besar pada spesimen, sehingga kedua materialnya terjadi ketidaksempurnaan dalam peleburan dan penyatuan. Nilai kekuatan tarik tertinggi terdapat pada arus $90 \mathrm{~A}$, karena masukan panas yang pas yang diberikan membuat kedua material mengalami peleburan yang sempurna sehingga ketika mengalami pendinginan terjadi penyatuan yang sangat baik. Hal ini sesuai jurnal Widyiatmoko, dkk (2017) dalam "pengaruh arus pengelasan las TIG terhadap karakteristik sifat mekanis stainless steel 304" yang menyatakan bahwa besar arus memberikan pengaruh kuat tarik Stainless steel type 304 pada proses las GTAW, akan tetapi pemberian arus yang berlabih dapat menurunkan hasil kakuatan tarik dari material dimana pada penggunaan arus 100 A terjadi perubahan hasil kekuatan tarik yang dikarenakan terjadinya daerah HAZ yang lebar sehingga menyebabkan terjadinya penurunan kekuatan tarik pada material. Hal ini sesuai dengan pernyataan Kumar dan Shahi (2011) bahwa hasil karakterisasi menunjukkan bahwa semakin arus yang digunakan menyebabkan penurunan kekuatan pada material. Lebih lanjut lagi menurut Wiryosumarto (1996) dimana arus listrik memberikan pengaruh yang sangat besar dalam proses penembusan dan penguatan. Arus yang terkecil dapat berakibat terjadinya penembusan dan penguatan rendah dan jika arus yang digunakan terlalu besar maka akan menghasilkan manik yang berbentuk sperti pir dan akan menjadi mudah terjadinya retak.

\section{ANALISIS STATISTIK}

Pengujian ini bertujuan untuk melihat seberapa besar nilai signifikansi yang diperoleh dari penggunaan variasi arus dan debit aliran gas pelindung terhadap kekuatan tarik. Data dari pengujian tarik sebelum dilakukan uji statistik analisis, terlebih dahulu dilakukan uji prasyarat yaitu Uji Normalitas data dan Uji Homogenitas. Uji Normalitas adalah sebuah uji yang dilakukan dengan tujuan untuk menilai sebaran data pada sebuah kelompok data atau variabel, apakah sebaran data tersebut berdistribusi normal atau tidak. Sedangkan Uji Homogenitas bertujuan untuk mengetahui apakah beberapa varian populasi adalah sama atau tidak.

Tabel 3. One Sampel Kolmogorov-Smirnov Test

\begin{tabular}{|c|c|c|}
\hline \multicolumn{3}{|c|}{ One-Sample Kolmogorov-Smirnov Test } \\
\hline & & $\begin{array}{l}\text { Hasil Kuat } \\
\text { Tarik }\end{array}$ \\
\hline N & & 18 \\
\hline \multirow[t]{2}{*}{ Normal Parameters ${ }^{a, b}$} & Mean & 581.8495 \\
\hline & Std. Deviation & 23.90161 \\
\hline \multirow[t]{3}{*}{ Most Extreme Differences } & Absolute & .128 \\
\hline & Positive & .114 \\
\hline & Negative & -.128 \\
\hline Test Statistic & & .128 \\
\hline Asymp. Sig. (2-tailed) & & $.200^{\mathrm{c}, \mathrm{d}}$ \\
\hline \multicolumn{3}{|c|}{ a. Test distribution is Normal. } \\
\hline \multicolumn{3}{|c|}{ b. Calculated from data. } \\
\hline \multicolumn{3}{|c|}{ c. Lilliefors Significance Correction. } \\
\hline \multicolumn{3}{|c|}{ d. This is a lower bound of the true significance. } \\
\hline
\end{tabular}

\section{Hipotesis}

Ho = Data berdistribusi normal

$\mathrm{Ha}=$ Data tidak berdistribusi normal

\section{Dasar Pengambilan Keputusan}

Jika nilai signifikansi Kolmogorov-Smirnov > 0,05, maka data berdistribusi normal Jika nilai signifikansi Kolmogorov-Smirnov $<0,05$, maka data berdistribusi tidak normal Keputusan 
159 Ahmad Saefudin, Abdul Qolik, Solichin - Pengaruh Variasi Arus Pengelasan dan Debit Aliran Gas Pelindung .....

Pada Tabel One Sampel Kolmogorov-Smirnov Test terlihat nilai probabilitas Asymp Sig (2 tailed) sebesar 0.200 > 0,05 maka data berdistribusi normal.

Setelah data berdistribusi normal maka dilanjutkan uji prasyarat yang kedua yaitu Uji Homogenitas. Pada uji homogenitas ini peneliti menggunakan uji levene's test.

Tabel 4 Uji Homogenitas

\begin{tabular}{|c|c|c|c|}
\hline \multicolumn{4}{|c|}{$\begin{array}{c}\text { Levene's Test of Equality of Error } \\
\text { Variances }^{\mathrm{a}}\end{array}$} \\
\hline \multicolumn{4}{|c|}{ Dependent Variable: Hasil Kuat Tarik } \\
\hline $\mathrm{F}$ & df1 & df 2 & Sig. \\
\hline 2.374 & 5 & 12 & .102 \\
\hline \multicolumn{4}{|c|}{$\begin{array}{l}\text { Tests the null hypothesis that the error } \\
\text { variance of the dependent variable is equal } \\
\text { across groups. }\end{array}$} \\
\hline \multicolumn{4}{|c|}{$\begin{array}{l}\text { a. Design: Intercept + Kuat_Arus + } \\
\text { Debit_Aliran_GAs + Kuat_Arus * } \\
\text { Debit_Aliran_GAs }\end{array}$} \\
\hline
\end{tabular}

\section{Hipotesis}

$\mathrm{HO}=$ Varian data adalah identik

Ha = Varian data adalah tidak identik

\section{Dasar Pengambilan Keputusan}

Jika nilai signifikansi atau probabilitas $>0,05$ maka Ho tidak di tolak

Jika nilai signifikansi atau probabilitas $<0,05$ maka Ho di tolak

\section{Keputusan}

Pada Tabel Uji Homogenitas diatas terlihat nilai signifikansi sebesar $0.102>0,05$ maka Ho tidak ditolak, dengan kata lain ketiga varian populasi adalah identik atau sama. Dengan demikian, asumsi kesamaan varian untuk uji Two Way Anova telah terpenuhi.

Tabel 4.10 Data Two Way Anova Pengaruh Variasi Pengelasan Dengan Variasi Kecepatan Alir Gas Argon Terhadap Kekuatan Tarik Dan Kekerasan Stainless Steel 304.

\begin{tabular}{|c|c|c|c|c|c|}
\hline \multicolumn{6}{|c|}{ Tests of Between-Subjects Effects } \\
\hline \multicolumn{6}{|c|}{ Dependent Variable: Hasil Kuat Tarik } \\
\hline Source & $\begin{array}{c}\text { Type III Sum } \\
\text { of Squares }\end{array}$ & df & Mean Square & $\mathrm{F}$ & Sig. \\
\hline Corrected Model & $4862.503^{a}$ & 5 & 972.501 & 2.406 & .099 \\
\hline Intercept & 6093878.174 & 1 & 6093878.174 & 15079.582 & .000 \\
\hline Kuat_Arus & 3777.942 & 2 & 1888.971 & 4.674 & .032 \\
\hline Debit_Aliran_GAs & 989.122 & 1 & 989.122 & 2.448 & .144 \\
\hline $\begin{array}{l}\text { Kuat_Arus * } \\
\text { Debit_Aliran_GAs }\end{array}$ & 95.439 & 2 & 47.720 & .118 & .890 \\
\hline Error & 4849.374 & 12 & 404.115 & & \\
\hline Total & 6103590.051 & 18 & & & \\
\hline Corrected Total & 9711.877 & 17 & & & \\
\hline
\end{tabular}

\section{Hipotesis}

Ho : Tidak terdapat perbedaan rata-rata yang signifikan

$\mathrm{Ha}$ : Terdapat perbedaan rata-rata yang signifikan

Dasar Pengambilan Keputusan 
Jika nilai signifikansi $<0,05$, maka ada perbedaan hasil kekuatan tarik stainless steel 304 berdasarkan variabel vaktor atau Ho di tolak. Jika nilai signifikansi > 0,05, maka tidak ada perbedaan hasil kekuatan tarik stainless steel 304 berdasarkan variabel vaktor atau Ho tidak di tolak . Dari data di atas, pada kuat arus diperoleh nilai signifikansi sebesar $0.032<0,05$ sehingga dapat disimpulkan bahwa ada perbedaan nilai kekuatan tarik stainless steel 304 berdasarkan variasi kuat arus pengelasan atau H0 ditolak. Sedangkan untuk variasi debit aliran gas diperoleh nilai signifikansi sebesar $0.144>0,05$ sahingga dapat disimpulkan bahwa tidak ada perbedaan nilai kekuatan tarik stainless steel 304 berdasarkan variasi debit aliran gas atau H0 tidak ditolak.

\section{SIMPULAN DAN SARAN Simpulan}

Terdapat perbedaan yang signifikan penggunaan variasi kuat arus mempengaruhi kekuatan tarik stainless steel 304 dengan nilai signifikansi sebesar 0.032 yang lebih kecil dari nilai signifikansi $(0,05=5 \%)$ pada 3 variasi arus dari $80 \mathrm{~A}, 90 \mathrm{~A}, 100 \mathrm{~A}$. Kekuatan tarik tertinggi pada pengelasan GTAW dengan variasi kuat arus secara keseluruhan tedapat pada penggunaan arus 90 A. Tidak terdapat perbedaan yang signifikan penggunaan debit aliran gas pelindung mempengaruhi kekuatan tarik stainless steel 304 dengan nilai signifikansi sebesar 0.144 yang lebih besar dari nilai signifikansi $(0,05=5 \%)$ pada variasi debit aliran gas pelindung $8 \mathrm{~L} / \mathrm{min}$ dan $10 \mathrm{~L} / \mathrm{min}$. Kekuatan tarik tertinggi pada pengelasan GTAW dengan variasi debit aliran gas pelindung $8 \mathrm{~L} / \mathrm{min}$ dan $10 \mathrm{~L} / \mathrm{min}$ secara keseluruhan kekuatan tarik tertingginya pada debit $8 \mathrm{~L} / \mathrm{min}$.

\section{Saran}

Untuk mendapatkan hasil kekuatan tarik yang tinggi disarankan menggunakan kuat arus yang tidak terlalu besar dan juga tidak terlalu kecil. Dan untuk pemilihan gas pelindung disarankan menggunakan debit aliran gas yang kecil.

\section{DAFTAR RUJUKAN}

ASM Handbook (Revised Vol. 6). 1993. Welding, Brazing and Soldering. United State of America: ASM Internasional ASTM Internasional (E8/E8M - 09). 2010. Standard Test Methods for Tension Testing of Metalic Materials. United States of America

Dieter, George. 1988, Mechanical Metalurgy. New York: Mc Graw-Hill Book Company

Ismawan, Ashari. 2010. Pengaruh Debit Gas Argon dan Kuat Arus pada Sambungan Las Terhadap Kekuatan Tarik dengan Pengelasan GMAW. TesisTidak Diterbitkan. Malang: Universitas Muhammadiyah Malang

Kumar, S., A. Shahi. (2011).'Effect of heat input on the microstructure and mechanical properties of gas tungsten arc welded AISI 304 stainless steel joints". Materials \& Design. 32(6): 3617-3623.

Marihot, Goklas. 1984. Mengelas Logam dan Pemilihan Kawat Las. Jakarta: PT Gramedia

Sunarto. 2015. Listrik Magnet. Jakarta: Universitas Tri Sakti

Widharto, Sri. 2003. Petunjuk Kerja Las. Jakarta: PT Pradnya Paramita

Widyatmoko, Antonius. dkk. 2017. Pengaruh Arus Pengelasan Las Tig Terhadap Karakteristik Sifat Mekanis Stainless Steel Type 304. TRAKSI Vol. 17 No.1

Wiryosumarto,Harsono \& Okumura,Toshie. 2008. Teknologi Pengelasan logam. Jakarta: PT Pradnya Paramita. 